\title{
Checking the Geometric Accuracy of a Machine Tool for Selected Geometric Parameters
}

\author{
Adam Janásek ${ }^{1}$, Robert Čep ${ }^{1}$, Josef Brychta ${ }^{1}$ \\ ${ }^{1} V \check{S} B$ - Technical University of Ostrava, Department of Machining and Assembly, \\ 17. listopadu 15/2172, 70833 Ostrava-Poruba, Czech Republic
}

Correspondence to: adam.janasek@vsb.cz

\begin{abstract}
This paper deals with the control parameters for selected geometric accuracy measurements for a machine tool. The parameters were needed after a refurbished milling machine was purchased. After setting up the machine, it was necessary to check the geometric accuracy that can be used for precise milling. The whole check was performed in accordance with ISO 10791. Only selected parameters of geometric accuracy were inspected, and they were later compared with the prescribed values. On the basis of a comparison of these values we were able to determine whether the machine tool can be used for accurate machining.
\end{abstract}

Keywords: geometric accuracy, testing, milling machine.

\section{Selected geometric parameters}

The measurements were performed on a vertical spindle milling machine, see Figure 1. For this milling machine, we selected eight geometrical accuracy tests from the ISO 10791-2 standard for a machine with a vertical spindle, and two accuracy tests for horizontal milling machines. For each geometric accuracy test, we performed at least as many measurements as were stipulated in the standard. Before each measurement was performed, the gauge adjustment required for the specific test was made, and surface cleaning was done (on the measured surfaces). The tests were performed at a constant temperature of $20^{\circ} \mathrm{C}$. The test scheme is shown for each test of geometric accuracy from the ISO 10791-2 standard. Further tests were supplemented by an individual value, as allowed by the ISO 10791-2 standard.

Tests performed on the milling machine: [1]

a) Measurement of periodic axial spindle movement on the lateral surface, test G10b.

b) Measurement of periodic axial spindle movement, test G10a.

c) Measurement of peripheral whipping - internal taper spindle at the end of the spindle, test G11a.

d) Measurement of peripheral whipping - internal taper spindle at a distance of $110 \mathrm{~mm}$ from the end of the spindle, test G11b.

e) Measurement of axial parallelism with spindle movement on the $Z$ axis, test G12.

f) Measurement of the angular deviation movement on the $Y$ axis, test G5a. g) Measurement of the angular deviation movement on the $X$ axis, test G4a.

h) Measurement of the middle guide groove - parallel to the table feed at a distance of $500 \mathrm{~mm}$, test $8 \mathrm{a}$ and measured opposite side of the guide groove, test $8 \mathrm{~b}$.

i) Measurement of the movement parallelism on the $Y$ axis with the table surface, distance $Y=$ $170 \mathrm{~mm}$, test G17.

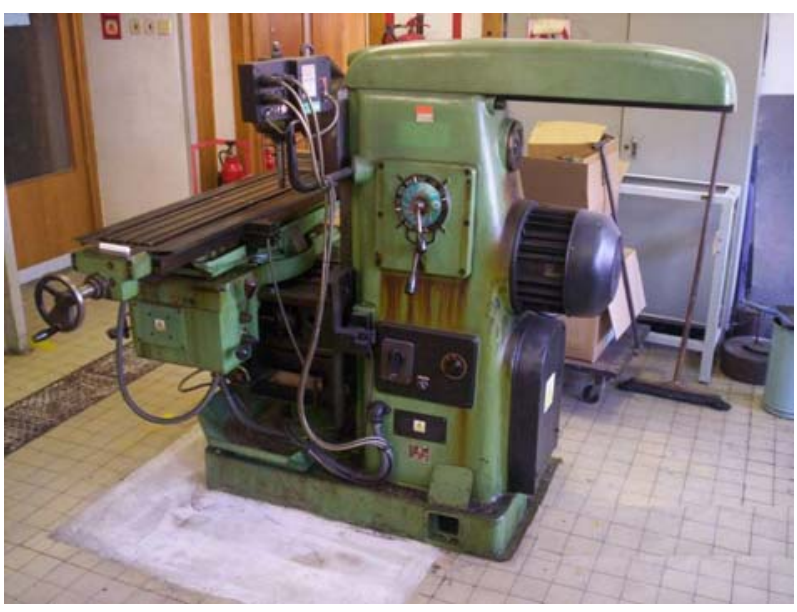

Figure 1: Tested milling machine with a vertical spindle - side view [3]

\section{Test G10B}

This test was conducted on a radius of $A=40 \mathrm{~mm}$. The measurement was based on the fact that the dial indicator was attached to the lateral surface of the 
spindle, and deviation can be controlled thanks to the rotation of the spindle. Before making the measurements we had to remove the drag-stones, which are hindered by the measurements. Ten measurements were performed, and the values were processed.

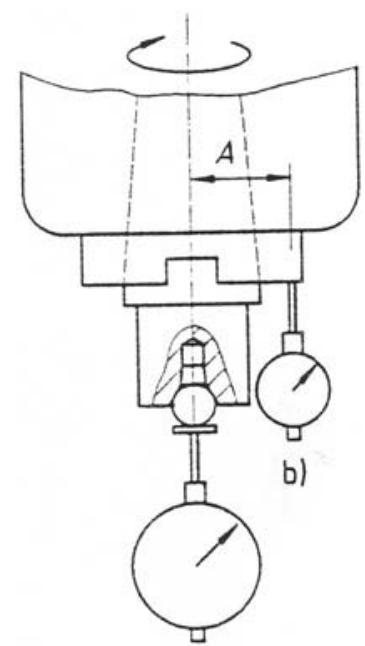

a)

Figure 2: Measurement scheme [1]

$$
\begin{aligned}
u_{A} & =\sqrt{\frac{\sum_{i=1}^{n}(X i-\bar{X})^{2}}{n \cdot(n-1)}}=8.33 \cdot 10^{-4} \mathrm{~mm} \\
X & =\bar{X} \pm u_{A} \\
X & =(0.00750 \pm 0.00083) \mathrm{mm}
\end{aligned}
$$

Measured value: $(0.00750 \pm 0.00083) \mathrm{mm}$ Value according to the standard: $0.01 \mathrm{~mm}$ The milling machine is satisfactory in terms of this test.

\section{Test G10A}

This test was conducted inside the spindle at a height of $10 \mathrm{~mm}$ above the drag-stones. The measurement was based on the fact that the dial indicator was attached to the internal surface of the spindle, and the deviation can be controlled thanks to the rotation of the spindle. Again, ten measurements were performed and the values were processed [3]. Finally, the drag-stones were remounted on the spindle.

$$
\begin{aligned}
u_{A} & =\sqrt{\frac{\sum_{i=1}^{n}(X i-\bar{X})^{2}}{n \cdot(n-1)}}=7.65 \cdot 10^{-4} \mathrm{~mm} \\
X & =\bar{X} \pm u_{A} \\
X & =(0.00350 \pm 0.00077) \mathrm{mm}
\end{aligned}
$$

Measured value: $(0.00350 \pm 0.00077) \mathrm{mm}$ Value according to the standard: $0.005 \mathrm{~mm}$ The milling machine is satisfactory in terms of this test.

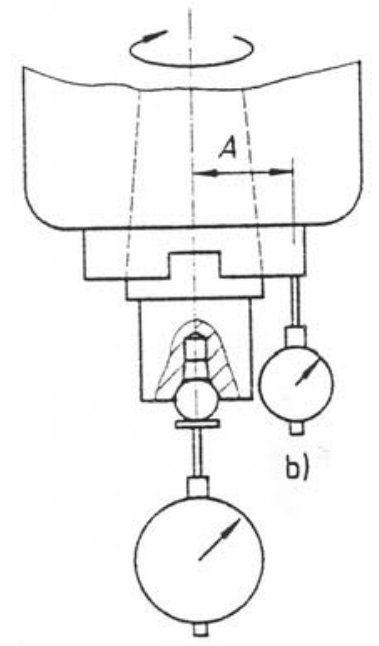

a)

Figure 3: Measurement scheme [1]

\section{Test G11A}

This test was conducted at the end of the spindle. The mandrel is clamped to the spindle and the peripheral whipping was evaluated. The perpendicular axis of the mandrel (or the spindle on the axis of the longitudinal feed table) was checked before starting the measurements [3]. Thus control was important for precise testing of the peripheral spindle whipping. The measurement was based on the fact that dial indicator was attached to the mandrel.

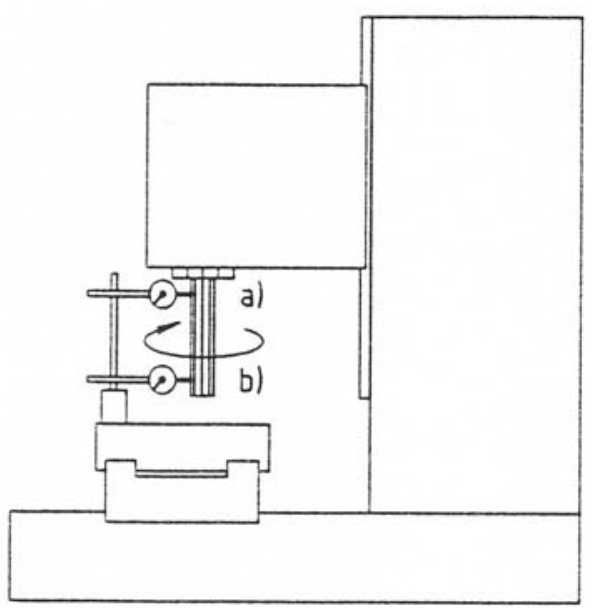

Figure 4: Measurement scheme [1]

$$
\begin{aligned}
u_{A} & =\sqrt{\frac{\sum_{i=1}^{n}(X i-\bar{X})^{2}}{n \cdot(n-1)}}=8.16 \cdot 10^{-4} \mathrm{~mm} \\
X & =\bar{X} \pm u_{A} \\
X & =(0.01300 \pm 0.00082) \mathrm{mm}
\end{aligned}
$$

Measured value: $(0.01300 \pm 0.00082) \mathrm{mm}$ Value according to the standard: $0.01 \mathrm{~mm}$ The milling machine is unsatisfactory in terms of this test. 


\section{Test G11B}

This test was conducted at a distance of $110 \mathrm{~mm}$ from the end of the milling spindle. The mandrel was clamped into the milling spindle, and peripheral whipping was carried out. It was not necessary to check the perpendicularity of the axis of the mandrel because this had been done in previous measurements. The measurements were taken after measuring at a distance of $110 \mathrm{~mm}$ from the end of the spindle and after establishing a magnetic pedestal with a dial indicator on the milling table. The measurements were based on the fact that the mandrel was attached to the dial indicator and the deviation was controlled during rotation. For this test, it was necessary to convert the allowed values according to [1], because the tolerance on a measured length of $300 \mathrm{~mm}$ is given by the standard [3]. Our measurement was performed on a length of $110 \mathrm{~mm}$.

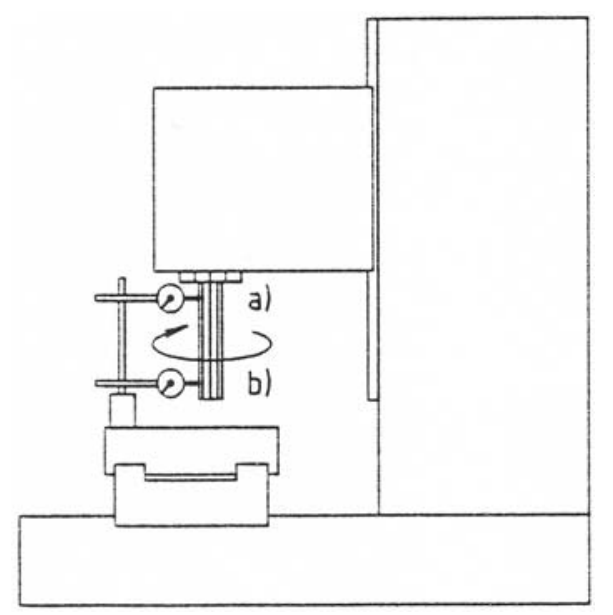

Figure 5: Measurement scheme [1]

$$
\begin{aligned}
u_{A} & =\sqrt{\frac{\sum_{i=1}^{n}(X i-\bar{X})^{2}}{n \cdot(n-1)}}=8.5 \cdot 10^{-4} \mathrm{~mm} \\
X & =\bar{X} \pm u_{A} \\
X & =(0,02300 \pm 0.00085) \mathrm{mm}
\end{aligned}
$$

Conversion of standard values for length $110 \mathrm{~mm}$ : length $300 \mathrm{~mm}$ allows $0.01 \mathrm{~mm}$ according to $[1] \Rightarrow$ allowed $1 \mathrm{~mm}$ on: $0.01 / 300=3.33 \cdot 10^{-5} \mathrm{~mm} \Rightarrow$ $110 \mathrm{~mm}=0.014 \mathrm{~mm}$

Measured value: $(0.02300 \pm 0.00085) \mathrm{mm}$ Value according to the standard: $0.014 \mathrm{~mm}$ The milling machine is unsatisfactory in terms of this test.

\section{Test G12}

This test was conducted at a distance of $110 \mathrm{~mm}$. The mandrel was clamped to the milling spindle and axial parallelism was carried out with spindle move- ment on the $Z$ axis. Measurements were taken after measuring a distance of $110 \mathrm{~mm}$ and after establishing a magnetic pedestal with a dial indicator on the milling table. Ten measurements were performed at position $0^{\circ}$, and the next ten measurements were performed at mandrel rotation $180^{\circ}$, in order to eliminate errors resulting from inaccuracies of the mandrel itself. For this test, it was necessary to convert the allowed values according to [1], because the tolerance given by the standard is for a measured length of $300 \mathrm{~mm}$. Our measurement was performed on a length of $110 \mathrm{~mm}$.

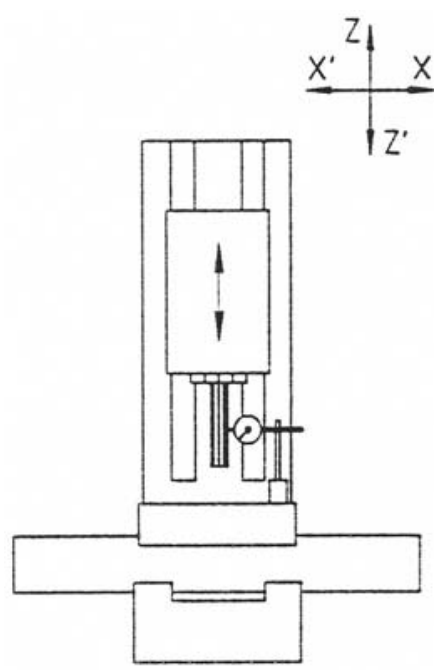

Figure 6: Measurement scheme [1]

$$
\begin{aligned}
u_{A} & =\sqrt{\frac{\sum_{i=1}^{n}(X i-\bar{X})^{2}}{n \cdot(n-1)}}=8.16 \cdot 10^{-4} \mathrm{~mm} \\
X & =\bar{X} \pm u_{A} \\
X & =(0.00300 \pm 0.00082) \mathrm{mm}
\end{aligned}
$$

Conversion of standard values for length $110 \mathrm{~mm}$ : length $300 \mathrm{~mm}$ allows $0.015 \mathrm{~mm}$ according to $[1] \Rightarrow$ allowed $1 \mathrm{~mm}$ on: $0.015 / 300=5 \cdot 10^{-5} \mathrm{~mm} \Rightarrow$ on $110 \mathrm{~mm}=0.0055 \mathrm{~mm}$

Measured value: $(0.003 \pm 0.00082) \mathrm{mm}$

Value according to the standard: $0.0055 \mathrm{~mm}$ The milling machine is satisfactory in terms of this test.

\section{Test G5A}

This test was conducted at a distance of $1000 \mathrm{~mm}$ and was performed in the transverse direction. A coincidence spirit level was set up on the milling table, and was gradually placed at three locations. First, on the right side of the table, then in the middle, and finally on the left side. In each of these positions we gradually made ten measurements. After these measurements, the coincidence spirit level was rotated $180^{\circ}$, and the measurements were again per- 
formed ten times in the same places [4]. The measurements were based on the fact that the examined deviation of each of the halves inside the coincidence spirit level and the deflection were recorded at the time when the two halves for the spirit level were established [2]. The resultant values were obtained by differential measurements of the maximum and minimum values.

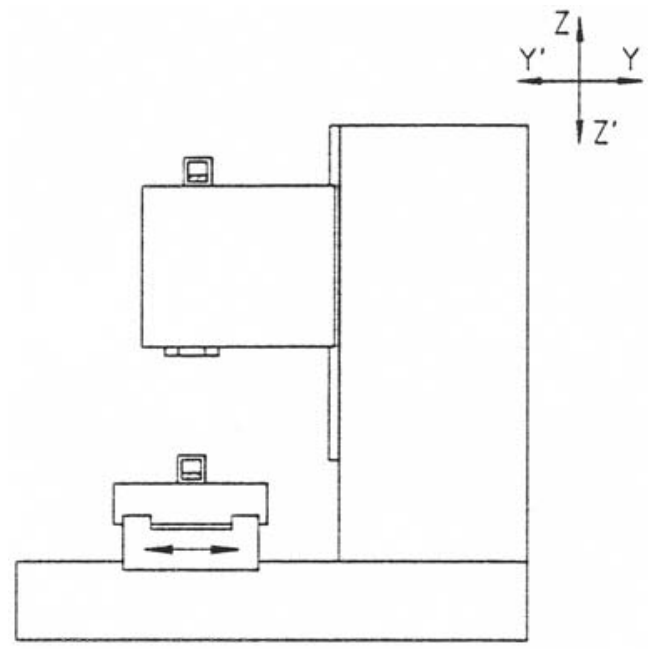

Figure 7: Measurement scheme [1]

$$
\begin{aligned}
u_{A} & =\left(u_{A P}+u_{A L}\right) / 2 \\
X & =X_{\max }-X_{\min } \\
X & =X_{P}-X_{L}=(0.1900 \pm 0.0047) \mathrm{mm} \\
u_{A P} & =\sqrt{\frac{\sum_{i=1}^{n}\left(X i_{P}-\bar{X}_{P}\right)^{2}}{n \cdot(n-1)}}=4.43 \cdot 10^{-3} \mathrm{~mm} \\
X_{P} & =\bar{X}_{P} \pm u_{A P}=(2.1200 \pm 0.0044) \mathrm{mm} \\
u_{A S} & =\sqrt{\frac{\sum_{i=1}^{n}\left(X i_{S}-\bar{X}_{S}\right)^{2}}{n \cdot(n-1)}}=0.010089 \mathrm{~mm} \\
X_{S} & =\bar{X}_{S} \pm u_{A S}=(2.076000 \pm 0.010089) \mathrm{mm} \\
u_{A L} & =\sqrt{\frac{\sum_{i=1}^{n}\left(X i_{L}-\bar{X}_{L}\right)^{2}}{n \cdot(n-1)}}=5 \cdot 10^{-3} \mathrm{~mm} \\
X_{L} & =\bar{X}_{L} \pm u_{A L}=(1.930 \pm 0.005) \mathrm{mm}
\end{aligned}
$$

Measured value: $(0.1900 \pm 0.0047) \mathrm{mm}$ Value according to the standard: $0.04 \mathrm{~mm}$ The milling machine is unsatisfactory in terms of this test.

\section{Test G4A}

This test was conducted at a distance of $1000 \mathrm{~mm}$, and was performed in the longitudinal direction. A coincidence spirit level was set up on the milling table and was gradually placed at three locations. The order of the placements was as for the previous measurement. In each of these positions we gradually made ten measurements [3]. In essence, the prin- ciple of measurement was the same as in test G5a (above).

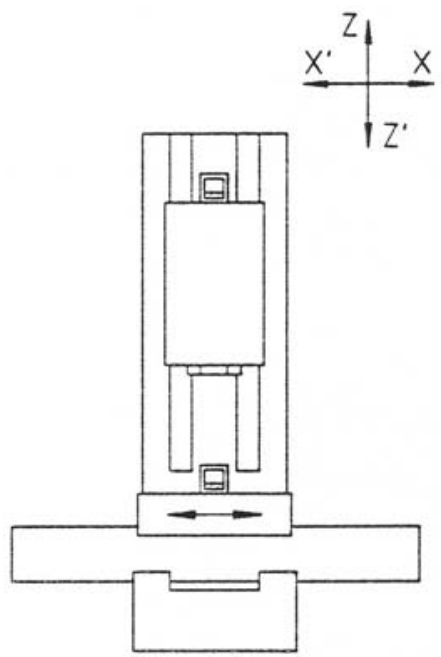

Figure 8: Measurement scheme [1]

$$
\begin{aligned}
u_{A} & =\left(u_{A S}+u_{A P}\right) / 2 \\
X & =X_{P}-X_{L}=X_{\max }-X_{\min } \\
X & =X_{S}-X_{P}=(0.2000 \pm 0.0095) \mathrm{mm} \\
u_{A P} & =\sqrt{\frac{\sum_{i=1}^{n}\left(X i_{P}-\bar{X}_{P}\right)^{2}}{n \cdot(n-1)}}=0.011 \mathrm{~mm} \\
X_{P} & =\bar{X}_{P} \pm u_{A P}=(2.630 \pm 0.011) \mathrm{mm} \\
u_{A S} & =\sqrt{\frac{\sum_{i=1}^{n}\left(X i_{S}-\bar{X}_{S}\right)^{2}}{n \cdot(n-1)}}=0.0079 \mathrm{~mm} \\
X_{S} & =\bar{X}_{S} \pm u_{A S}=(2.8300 \pm 0.0079) \mathrm{mm} \\
u_{A L} & =\sqrt{\frac{\sum_{i=1}^{n}\left(X i_{L}-\bar{X}_{L}\right)^{2}}{n \cdot(n-1)}}=0.0089 \mathrm{~mm} \\
X_{L} & =\bar{X}_{L} \pm u_{A L}=(2.7100 \pm 0.0089) \mathrm{mm}
\end{aligned}
$$

Measured value: $(0.2000 \pm 0.0095) \mathrm{mm}$ Value according to the standard: $0.06 \mathrm{~mm}$ The milling machine is unsatisfactory in terms of this test.

\section{Test $8 \mathrm{~A}$ and test $8 \mathrm{~B}$}

This test was conducted at a distance of $500 \mathrm{~mm}$. Individual measurements were performed after $50 \mathrm{~mm}$. The measurements were based on the fact that the magnetic pedestal was attached to the structure of the mill. The point of the dial indicator was attached to the surface side of the guide groove. The measured deflection was noted every $50 \mathrm{~mm}$ with the passing of the groove [5]. Then we measured the opposite side of the guide groove. The principle is exactly the same as in test 8 a (above). 


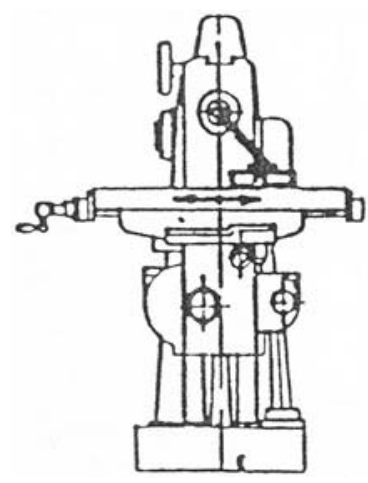

Figure 9: Measurement scheme [1]

$$
\begin{aligned}
u_{A} & =\sqrt{\frac{\sum_{i=1}^{n}(X i-\bar{X})^{2}}{n \cdot(n-1)}}=4.69 \cdot 10^{-3} \mathrm{~mm} \\
X & =\bar{X} \pm u_{A}=(0.0230 \pm 0.0047) \mathrm{mm} \\
u_{A} & =\sqrt{\frac{\sum_{i=1}^{n}(X i-\bar{X})^{2}}{n \cdot(n-1)}}=1.95 \cdot 10^{-3} \mathrm{~mm} \\
X & =\bar{X} \pm u_{A}=(0.0073 \pm 0.0020) \mathrm{mm}
\end{aligned}
$$

Measured value: $(0.0230 \pm 0.0047) \mathrm{mm}$

Value according to the standard: $0.02 \mathrm{~mm}$ The milling machine is unsatisfactory in terms of this test. (8a test)

Measured value: $(0.0073 \pm 0.0020) \mathrm{mm}$

Value according to the standard: $0.02 \mathrm{~mm}$ The milling machine is satisfactory in terms of this test. ( $8 \mathrm{~b}$ test)

\section{Test G17}

This test was conducted on the right and left side of the milling table. First, a ruler had to be assembled at a distance of $250 \mathrm{~mm}$ from the centre of the table to the right side and then on the left side of the milling table. Ten measurements were performed for the right side, and then ten measurements for the left side.

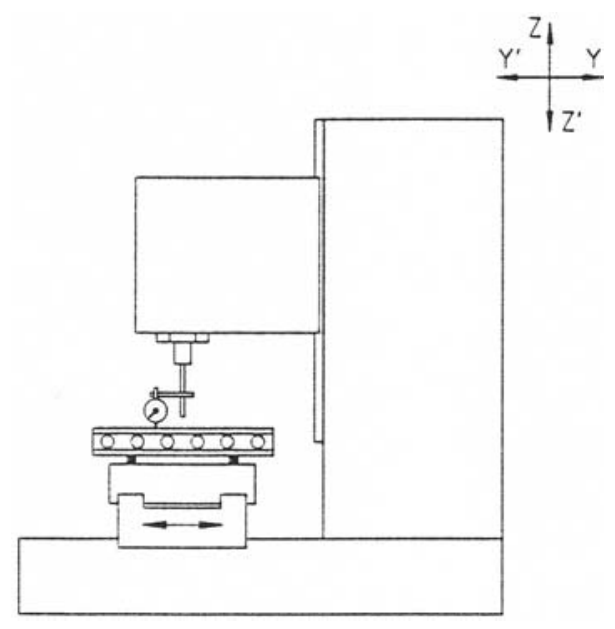

Figure 10: Measurement scheme [1]

$$
\begin{aligned}
u_{A P} & =\sqrt{\frac{\sum_{i=1}^{n}\left(X i_{P}-\bar{X}_{P}\right)^{2}}{n \cdot(n-1)}}=1.25 \cdot 10^{-3} \mathrm{~mm} \\
u_{A L} & =\sqrt{\frac{\sum_{i=1}^{n}\left(X i_{L}-\bar{X}_{L}\right)^{2}}{n \cdot(n-1)}}=8.16 \cdot 10^{-4} \mathrm{~mm} \\
X_{P} & =\bar{X}_{P} \pm u_{A P}=(0.0140 \pm 0.0013) \mathrm{mm} \\
X_{L} & =\bar{X}_{L} \pm u_{A L}=(0.00800 \pm 0.00082) \mathrm{mm}
\end{aligned}
$$

Measured value: $(0.0140 \pm 0.0013) \mathrm{mm}$ Value according to the standard: $0.02 \mathrm{~mm}$ Measured value: $(0.00800 \pm 0.00082) \mathrm{mm}$ Value according to the standard: $0.02 \mathrm{~mm}$ The milling machine is satisfactory in terms of these tests.

\section{Conclusions}

This paper has reported on tests of selected geometrical precision parameters for a milling machine in the laboratories of the Department of Machining and Assembly, Faculty of Mechanical Engineering, VŠB Technical University of Ostrava. The measurements were performed after selecting suitable tests and providing the necessary gauges and equipment for the tests.

On the basis of the results of the geometric precision tests for a milling machine with a vertical spindle, the following conclusions can be drawn:

- The milling machine failed 5 out of the 10 tests that were performed.

- Measurement of the middle guide groove, parallel to table feed at a distance of $500 \mathrm{~mm}$ (test 8a): the main reason for the unsatisfactory test results was the groove that ran through the whole side. The same measurement was therefore performed on the opposite side of the groove, and in this case c ompliance was achieved.

- Measurement of the angular deviation movement on the $Y$ axis (test G5a), and measurement of the angular deviation movement on the $X$ axis (test G4a): the main reason for the unsatisfactory test result was bad setting up in the laboratory. It was not possible to establish into the correct position, because the milling machine was not equipped with establishing screws.

- The peripheral whipping measurement - the internal taper spindle at the end of the spindle (test G11a) and the peripheral whipping measurement - the internal taper spindle at a distance of $110 \mathrm{~mm}$ from the end of the spindle (test G11b): the main reason for the unsatisfactory test result was perhaps gear-wear with a constant gear ratio inside the milling head, or bearing-wear. In order to eliminate this inac- 
curacy, it would be necessary to overhaul the milling head.

\section{Acknowledgement}

This paper is an outcome of project no. CZ.1.07/2.4.00/17.0082: Increasing of Professional Skills by Practical Acquirements and Knowledge, supported by the Education for Competitiveness Operational Programme, funded from European Union Structural Funds and from the state budget of the Czech Republic.

\section{References}

[1] ISO 10791-2 - Test conditions for machine centres - Part 2: Geometric tests for machines with vertical spindle or universal heads with vertical primary rotary axis (vertical $Z$-axis).
[2] Tichá, Š.: Strojírenská metrologie - část 1. Ostrava : VŠB - TU Ostrava, 2006, p. 112 ISBN 80-248-0671-1.

[3] Brázda, F.: Kontrola vybraných parametrů geometrické přesnosti obráběcího stroje. Ostrava : Katedra obrábění a montáže, 2006. Bakalářská práce. VŠB - Technical University of Ostrava. Bachelor project supervisor: Robert Čep.

[4] Čep, R., Janásek, A., Valíček, J., Čepová, L.: Testing of Greenleaf Ceramic Cutting Tools with and Interrupted Cutting. Tehnički Vjestnik - Technical Gazette. Vol. 18, no. 3, 2011, p. 327-332. ISSN 1330-3651.

[5] ISO 10791-1 - Test conditions for machine centres - Part 1: Geometric tests for machines with horizontal spindle and with accessory heads (horizontal $Z$-axis). 